\title{
The Innovative Models of C-trip's E-commerce
}

\author{
Qilun Zhang, Yang Wang \\ School of Administrative Management, Beijing Institute of Economics \& Management, No.12,Huajiadijie Street, Chaoyang \\ District, Beijing, PR.China \\ qilunzhang@biem.edu.cn, wangyang720@sohu.com
}

\begin{abstract}
In the market of the on-line travel agencies, many new concepts and even commercial models emerge these years. Facing the big challenging of the Qunar. Net \& Baidu's integration, the C-trip is quite hard to move forward. Yahoo, eBay, Google are on the multiple ways, but the C-trip is devoted herself to go her professional way. Following the model, the only one, she will learn from Starbucks, Wal-Mart and McDonalds's to do so. C-trip has to be more innovative and creative in a long run, including her culture and inter-management, otherwise, she can not be adaptive and sustainable. This paper is aiming at the C-trip's innovative model to analyse the features and significance. The research may follow the mega-company's development to dig the other special and sustainable value-sectors. It's just a guiding-way to say something to the other on-line travelling corporations.
\end{abstract}

Index Terms - innovative model, innovative platform

\section{Introduction}

C-trip was founded in 1999, the Shanghai-based company provides services including hotel reservations, flight ticketing, and packaged tours[1]. C-trip firstly is a travel service company; her commitment is to serve well for the tourism. Culturally, her right way is like this. In other word, she borrows the internet to market herself and serve to the innerpartners. Please do not mislead, C-trip is firstly travel service agency then an on-line internet enterprise. Her focus is to provide service to users via internet. It will be aimless to battle with on-line market share in terms of tourism industry. Her special culture should be modest and practical.

Facing many challenges, too many e-shops emerge one day, then a lot lose one night.B2B, B2C, and C2C e-commerce modes, like dandang.com, taobao.com and qunar.com make Ctrip sometimes embarrassed, however, C-trip is still stick to its professional mode [2]. .

C-trip.com, a leading online travel agency, has introduced many kinds of group tours and self-guided tour routes. As household incomes grow Chinese are spending more on travel -- the travel market is expected to grow from 1.5 trillion yuan in 2010 to 5.5 trillion yuan by 2020 , or over $\$ 870$ billion. That translates into a 14 percent annual growth rate for the Chinese travel industry. The volume is too big for C-TRP to monitor in realty.

C-trip's outstanding customer service has borne fruit, as it has become the clear leader in online travel services over competitors like E-long whose major stakeholder is Expedia. China's middle and upper classes are burgeoning. The ranks of the middle class are estimated to top 500 million by 2015. As Chinese become wealthier and increase their purchasing power they have certain desires. As international and domestic travel in China become affordable for more people, demand for travel services is going to increase. C-trip is well positioned to take advantage of this trend [3].

However, Baidu, China's largest search engine, trumpeted the astonishing growth of its travel site Qunar.In the fourth quarter Qunar became China's largest internet retailer of airline tickets - overtaking C-trip, the dominant online travel agency [4].

C-trip is much larger in scale, admitted Cui. E-long can never beat it by copying C-trip's business. As a result, E-long chose to focus on the hotel reservation market segment, targeting the No.1 spot in this vertical market. Moreover, Elong changed its advertising slogan (translated into English) to: "Booking Hotel, Go to e-Long."According to Cui, the growth rate of E-long in the hotel reservation business has exceeded that of C-trip for three concessive years.

As a matter of fact, the C-trip is already having a good preparation to challenge all of these competitors; the only way is to stick her own way professionally in tourism service online.

Clearly, the increasingly affluent Chinese are travelling and spending more than ever before. Combine that with the fact that China has the number-one Internet market in the world, and there's no denying that online travel company, Ctrip.com (C-TRP), is well positioned to profit. Despite China having the largest amount of Internet users in the world with 338 million users, only about $10 \%$ of China's travel plans are booked online. To me that spells opportunity, as online travel in China clearly has tremendous room for growth. Prior to the rise of the Chuppies (China's growing yuppie population), most Chinese tourists travelled in groups. But today, most Chuppies are too sophisticated and confident to travel in large tour groups.

In fact, an overwhelming 97\% of the Chuppies that my analysts and I surveyed prefer to travel independently instead of with a tour group. And C-trip.com caters to such travellers.

Established in 1999, C-Trip has grown into the leading online consolidator of hotel rooms and airline tickets in China. It currently dominates the online travel industry with a $60 \%$ market share in China's travel market.

C-trip's main competitor is Barry Diller's Expedia. But despite pouring \$167 million into China during the past two years to catch up, Expedia's China spin-off, e-Long is still playing catch up. And high entry barriers such as a fragmented travel industry that has no centralized reservations database, along with its first-mover advantage, will protect C-trip from competitors and maintain its dominant industry position. 


\section{Innovative Models of C-Trip}

The fact remains that C-trip does online travel better than any of its competitors in China and that its business has a lot of room to grow along with China's middle class. In future years, C-trip will benefit by focuses on building its corporate travel business and on expanding services from 1st tier cities like Beijing and Shanghai into 2nd tier cities like Chongqing and Dalian. C-trip is also becoming more efficient in its business model and in October is making air ticketing entirely electronic. This should cut costs and improve margins [5].

C-trip mixed a brick and mortar operation with technology quite well. To offset worries about e-commerce and a lack of credit card usage in China, for instance, C-trip delivered tickets to a home or office by courier where consumers could pay in cash.

C-trip's success is mainly due to her tourism professional mode. Since many years ago, C-trip has been obeying her own way like "deep-dig and careful-plant". The co-founder, Jianzhang Liang said that C-trip should learn from Walmart, Stubark, and McDonalds' s in a single way professionally, but not from Yahoo.com, eBay and Google in multiple-ways, the professional way is her long way to go, until C-trip becomes the most professional tourism-service company in case nobody can copy her [6].

At the beginning, Liang and his colleagues are aiming at building up an e-commercial company for tourism industry, but she doesn't belong any existing e-commerce modes.B2B B2C $、$ C2C all these modes cannot adapt C-trip's concept. She will be definitely a kind of e-service business [7]. C-trip set up an e-platform between $\mathrm{B}$ and $\mathrm{C}$, this platform is transforming the related traveling information and service, not commercial goods or products. It is not a real e-commerce trade, but an onor-off-line service system. C-trip benefits $30 \%$ from on-line booking in terms of hotel reservation, this business does not need delivery nor payment on-line, the other $70 \%$ benefits are from off-line telephone service in both room reservation and flights booking. She will benefit more and more by this sustainable relationship with the related industries like hotels and aviation companies. C-Trip's Call centers were automated for some parts of a sale but also had live and well-trained operators that made consumers feel comfortable buying tickets from someone other than the travel agent they were used to. After speaking with Neil, I was convinced that C-trip was a company investors should keep their eyes on.

C-trip has also begun focusing on corporate accounts, which should help fuel more sales. Companies in China still place a premium on conducting business face to face. C-trip will continue to benefit, especially as many secretaries in companies are deciding which travel agencies to work with. They often choose C-Trip because it has a very good loyalty program, akin to Starwood's Preferred Guest program that Chinese like and which I wrote about in Business Week recently.

\section{Another Innovative Model-Unifying the Whole Market of the Cyber-Marketing Channels Nits}

It truly unifies the cyber-market.Especially the unified price is quite important for C-trip presently. If C-trip can help cease the price war, she will be more influential in the operation tourism agencies; however, she cannot do that right now. C-trip's cheap price and other agencies' direct search service have the same space in intergrowth. Her most advantage is the relatively cheap price, the mainly reason why the tourists choose C-trip is that she has wonderful after-sale service, especially for the enterprise users and business tourists. They greatly rely on C-Trip's excellent tourism management service [8]. If C-Trip only sell information to both consumers and suppliers, she cannot live longer in this case. C-Trip develops into an internet tourism service supplier, she should not be that kind of intermediary institution, but the very professional service supplier. Mislead information and special resource can be sometimes a little beneficial for the reason that trading cost is existing from the beginning to the end, but cannot be like that all the time and in a long run, just because of the transparency market will be coming sooner or later. C-Trip was formerly playing an intermediary channel agency, but would not be the same role now and later in terms of her longevity. C-Trip's utmost goal is to enhance the effectiveness of the people's business and life, is to meet up with their real needs mentally and physically [9].

Another fringe benefit that has served C-Trip well has been its introduction of VIP cards that offer discounts at select restaurants and shopping destinations. Chinese consumers especially appreciate value added services like discounts at restaurants and this kind of well executed loyalty program is a great lure for customers. They have launched effective marketing campaigns by passing out membership cards at airports and train stations.

\section{Integrating}

The Innovative model has been integrating the related information and taking the advantages of the core resources are the most important factors which can influence the tourism cyber-market.

Superficially, C-trip is serving for the hotels and aviation companies by providing travel agency service, but profoundly, her position is quite clear, that is, an information integrator of the upper and lower operators along the industry. Unmatched information can lead to the low effeteness for the market economically. However, the transparency informed market can play a very dynamic role in the potential market and economical power. She bridges the suppliers with those needy consumers. With the opening scale and her acceptance of the new technologies, the adaption ability towards the information era and her learning captivity in new commercial models, particularly the innovative desire and drive, C-trip push herself forward greatly in terms of the gap between the other giant travel agencies. The most successful point totally owns to our opening thought and awareness, not to those closing and old concepts. 
Tourism Cyber-marketing is relying on the on-line service communicators, computer technologies, telephone communications and digital inter-related Medias etc. in order to make its utmost goal come true. Actually, it is focusing on connecting the tourists with the agency directly based on computers internet technologies; it can supply better tourism products and service to the tourists. C-trip is the leading guide in this respect.

Furthermore, C-trip is good at supplying excellent service for the business tourism. It includes the total tour from hotelrooms reservation, flights booking, business vocation management and even tourism inquiring [10]. C-trip extends the chain by offering information service and other related business tourism service. This is quite accessible and convenient for the business tourists.

\section{Advanced Management System and Innovative Service Models}

At present, C-trip is a mega-giant enterprise in on-line tourism service, she occupies more than $50 \%$ shares, is totally a leading marketing sector [11]. Tourism service is existing among the whole process including information offering and transforming, before-sale service and after-sale service [12], not just an intermediary gainer for that middle-man's fee.

In terms of management, the oriental countries and western ones have totally different views. Chinese enterprises pay much attention to someone's leading wisdom, team spirit and go all out to do a business. Western ones focus on systematic regulations. In that case, C-Trip chooses to build up regulated system in terms of management. The commercial operation models are quite important for both herself and her competitors. This is just a start to place emphasis on models, set-up points, competing captivity and potential ability in seeking after much progress in the foreseeable future. The issue of Chinese enterprise's management has always been problematic. They are influenced by both traditional culture and western management theory, but absorbing is not easy in real practice. To keep up with the tide, C-Trip dedicated herself to operate her own operation mode, by going deep in her modes how she shapes her operation methods and behaviours, C-Trip is trying hard to shed some light on future reform of C-Trip's development in playing an decisive role in Chinese tourism industry service. She will develop herself rapidly to continuously occupy a pivotal position in tourism industry in providing not only information technologies and many kinds of tourism operation platforms, even promoting technological communication innovation in E-commercial mode [13].

Many other tourism E-commercial companies' failure was due to overly ambitious expansion policies, too much spending on price war, property protection and short-eyed commercial multiple investments. The price war between two Chinese online travel companies C-trip.com (NASDAQ: CTRP) and eLong.com (NASDAQ: LONG) in 2012 has lead to huge losses for both. C-trip announced last July it would invest $\$ 500$ million into low price promotion lasting for the following year, which caused significant net profit drop in the third quarter 2012 - a total 40 percent. Nevertheless, e-Long also paid a lot for the price war as the sales and marketing costs of E-long has grown by 110 percent to $\$ 144.7$ million in the third quarter of 2012 from the $\$ 69$ million over the same period in 2011, which resulted in a $\$ 33.1$ million deficit of eLong in the long challenge [14]. How to achieve localization of operation system, how to become most powerful in both software and hardware, C-Trip has always been seeking after these goals. C-Trip understands that there are great differences in operation activities for people of different background, morality, values, and communication style. Some ones only drive for achieving effect, but any operation without culture adaption is not workable in practice.

\section{The Functional and Innovative Modes of C-Trip}

In terms of the C-Trip's influence in China tourism industry, she has synthesized the most valuable operation points and e-commerce operation modes in a scientific way. Due to the long time incompetence of the government to offer, many tourism operators do not trust the government. Therefore, it is quite understandable that Chinese generally prefer some e-commerce enterprises to official e-commerce nets. This tourism operation organization usually has cost single form of business operation can have the lowest cost. By C-Trip's e-commerce platform, good collaboration bases on trust. Therefore trust is an important factor to maintain operational effectiveness and keep operational survival. To keep going, C-Trip is focusing on designing the company's regulations and principles; on the other hand, she is to sermon to herself. Therefore C-Trip's staff are good at introspection, easy to communicate, and easy to carry out a comprehensive self-management. This mode is what C-Trip Company initiates and finds effectiveness to strengthen her internal management and help her to create numerous miracles.

C-Trip is in line with the "lowest agency costs principle. Then she will lower the management cost by reducing conflict and therefore improve the effectiveness of management. However, there is a hard nut to crack for C-Trip in the future.

\section{The Features of the C-Trip's Commercial Models}

Without caring any modes, whether you use fork or knife or chopsticks, the most functional one is to use the instruments quite functional and beneficial in larger scale, in higher layers of the mechanism. C-Trip is an OTA tourism agency, she leads the on-line tourism world. Her IOS app software is very advanced, this software advanced many other OTA company many years. From this, each tourist can know the time of the former flight, it can give any tour groups much accessible service individually. This property industry, C-Trip invest much more, for example, She bought Hong Kong Yongan Company, and later then she marketed her special product 'the program of Hong Kong City tour'., then the other one ' Hainan City Tour'. She has hundreds of buses for sightseeing. By package-tour airline, package tour service, she makes a lot of money. Furthermore, C-Trip controls the hotel reservation 
system of China powerfully. The supplying of package tour service and suppliers mode create many kinds of term account, this needs derivative instruments to run these financial operation for more benefits.

\section{The Commercial Features of the C-Trip's Innovative Models}

The innovation of the C-Trip's commercial mode means that any organizations offer basic and logical changes innovatively, it includes factors' change and transformation between these factors and dynamic mechanism. That is to say, any new and created methods and modes must be beneficial most.

(1) From the customers' view, the enterprise should aim at designing the behaviors of the enterprises. The vision has more extroversion and to be opening. In other word, it can offer the clients additional value. This is a basic idea. Logically, the point is how to meet up with the clients' needs, how to make them effective, this is totally different with technologies' innovation, C-Trip's innovative mode is related with technologies ,but the focus is on the economical factors and accessibility, not the technology itself.

(2) This mode shows that it could be more systematic and basic, it is not only the change of some factors. I t reflects many factors' great changes, this needs most strategic modifications, that is to say, a kind of collectiveness innovation. It dedicates by the service innovation, including service contents - methods and its organizational innovative operation ways.

(3) From the performance view, the totally new products or services may create a brand-new trend in beneficial industrial area. At least, the enterprises can gain the power of competence and dynamical abilities. The formation of the traditional innovation can make the internal effectiveness more functional and lower costly. The worst is that the other enterprises can be easily to copy.

Therefore, C-Trip has to be more innovative and intelligent , the final aim is to be a more professional and functional tourism on-line service company, not just a middleman.

\section{Conclusion}

In the future, C-Trip, the online travel agency in a professional and innovative way, claimed to have invested $\$ 500$ million to wave a year-long promotion campaign, as previously reported by International Financial News. However, such details were not confirmed in the firm's second quarter financial results reports released on July 24 [15].

Despite being the number-one online travel company in China, C-trip's business continues to grow. The company recently posted better-than-expected second-quarter results with its per-share profits increasing from 25 cents to 33 cents. That's well above analysts' projections for 29 cents.
Sales also walloped analyst's estimates, increasing $28 \%$ to $\$ 70$ million, nicely above the $\$ 64.5$ million projections. The boost in sales was a direct result of increases in air ticketing revenues and hotel reservation revenue, up $32 \%$ and $16 \%$ respectively.

And C-trip's management is looking for even more growth going forward, projecting to grow around $25 \%$ in the third quarter. Plus, the company should greatly benefit from the 2010 Shanghai World's Fair, which could bring 70 million people to the event. Now, that's going to boost hotel reservations in Shanghai and the surrounding area - and you can bet a good portion of these attendees will book their hotels online. So China's number-one online travel company still has plenty of room to grow, equalling incredible profits for investors. Shares are already up $112 \%$ year to date - and this is just the beginning. C-trip still has large gap to catch up the innovative train.

\section{Acknowledgment}

Thanks to Yang Wang, my colleague, for her supportive remanding, in that, the truly and non-abstract innovative models could be presented here.

\section{References}

[1] Anonymous, C-trip.com to expand overseas reservation services, Access on line on August 17,2012, www.chinadaily.com.cn

[2] D. Chen, The situation and resolutions of the Chinese tourism's ecommerce, The Journal of the Guide of the Economy Research, January of 2006.

[3] J. Tang, C-trip.com hits 52-week low, downgrade hurts, June 12,2012, Access on line: www.chinadaily.com.cn

[4] S. O'Neill, Qunar overtakes C-Trip as China's biggest travel site, booming on mobile sales, February 5, 2013, access on line, www. tnooz.com

[5] S. Rein, The end of cheap China: Economics and cultural trends that will disrupt the world, John Wiley \& Sons Publish House, USA,2010

[6] Y.Su, C-trip: a successful model, The Journal of Investment \& corporation, April of 2004

[7] G. Wang, The Reformation of the On-line Economy and Travelagencies' Commercial Models, The Journal of Business Economy and management, July of 2000

[8] A. Lin, C-Trip's traditional business is facing the challenge and also transforming into her tourism business service into the whole industry chain, IT Times Weekly, Vol.2, 2009

[9] X. Feng, The puzzle of the platform and channel, Digest of the Economy and Management, Vol.16, 2009

[10] J. Zhang, L.Lan, and Y.Chen, The analysis of the on-line business in terms of influencing tourists' decision-making-take the case of C-Trip, The Journal of Modern Commercial Business Industry, Vol.8, 2008.

[11] J. Wen, The Dream and puzzle of Min Fan, The Journal of Shanghai Economy, Vol.8, 2010

[12] J.Tan, The research about the business models of our tourism ecommerce enterprises, The journal of E-Commerce, Vol.11, 2012.

[13] R.Hsu, How to Profit from China's Travel Industry, Access on August 25, 2009, www. Investorplace.com

[14] X. Kang, E-Long challenges C-Trip, online travel companies trapped in price war, Access on Feb. $1^{\text {st }}$, 2013, www.chinadaily.com.cn

[15] Z.Liu, China's tourism integrity union established, Access on July 25, 2012. www.chinadaily.com.cn 